\title{
Analisis Ambang Batas Lahan Pemakaman di Kota Makassar
}

\author{
*Kartini, Nur Syam AS, Fadhil Surur
}

Jurusan Teknik Perencanaan Wilayah dan Kota, Universitas Islam Negeri Alauddin Makassar

*kartini871@gmail.com

\section{INFO ARTIKEL}

\section{Riwayat Artikel:}

Diterima: 08-08-2019

Disetujui: 21-11-2019

\section{Kata Kunci:}

Ambang batas

Kematian

lahan pemakaman

\section{ABSTRAK}

Abstrak: Peningkatan jumlah penduduk Kota Makassar dari tahun 2014-2016 berbanding lurus dengan peningkatan jumlah kematian sehingga kebutuhan lahan untuk pemakaman tiap tahunnya ikut meningkat. Populasi penduduk yang semakin bertambah dan akan mengalami kematian setiap saat tentu memerlukan sebuah lahan yang dijadikan sebagai sarana pemakaman umum, terkhusus untuk seorang muslim yang ketika meninggal akan dikubur sedangkan lahan pemakaman saat ini semakin terbatas. Hal ini menunjukkan adanya gap antara jumlah kematian dan luas lahan pemakaman yang tersedia sehingga muncullah beberapa permasalahan tentang lahan pemakaman. Tujuan dari penelitian ini adalah untuk mengetahui besar ambang batas lahan pemakaman umum Islam di Kota Makassar dan menyusun arahan perencanaan dalam pengembangan pemenuhan kebutuhan lahan pemakaman ditinjau dari aspek tata ruang. Metode yang digunakan adalah analisis deskriptif, proyeksi penduduk dan daya tampung sebagai ambang batas lahan pemakaman. Hasil dari penelitian ini menunjukkan bahwa ambang batas lahan pemakaman umum Islam di Kota Makassar masih mampu menampung jumlah kematian hingga tahun 2023 dengan sistem normal sedangkan untuk sistem tumpuk mampu menampung hingga tahun 2029. Arahan perencanaan dalam pengembangan pemenuhan kebutuhan lahan pemakaman ditinjau dari aspek tata ruang dengan pengoptimalisasian lahan pemakaman, sistem penumpukan makam, hutang lindung sebagai tempat pemakaman umum, pemakaman berdiri, pemindahan makam, pembuangan abu kremasi, pemakaman terpadu dan ideal.

Abstract: The increase in the population of Makassar City from 2014-2016 is directly proportional to the rise in the number of deaths so that the need for land for burial annually increases. The population that is rising and will die every time certainly requires an area that is used as a means of a public funeral, especially for a Muslim who, when he died, will be buried while burial land is now increasingly limited. This shows that there is a gap between the number of deaths and the area of available burial grounds so that several problems arise about burial grounds. The purpose of this study is to determine the threshold level of Islamic public cemeteries in Makassar City and prepare planning directions in developing the fulfillment of burial land needs in terms of spatial aspects. The method used is descriptive analysis, population projection, and capacity as a burial threshold. The results of this study indicate that the threshold level of Islamic public cemeteries in Makassar City is still able to accommodate the number of deaths up to 2023 with the conventional system, while the stack system can accommodate up to 2029. Planning direction in developing the fulfillment of burial land needs in terms of spatial aspects with optimizing burial ground, burial system, burial debt as a public burial place, standing burial, removal of the grave, disposal of cremation, integrated and ideal funeral. 


\section{A. LATAR BELAKANG}

Manusia adalah makhluk pilihan yang dimuliakan oleh Allah dari makhluk ciptaan-Nya yang lain (Sada, 2016). Makhluk Allah SWT yang memiliki keunggulan dan segala keistimewaan seperti akal yang mampu membedakan antara yang baik dan yang buruk (Amin, 2011). Al-Quran menjelaskan bahwa manusia diciptakan dari tanah dengan bermacam-macam istilah, seperti : Turaab, Thieen, Shal-shal, dan Sulalah (Sada, 2016). Setiap manusia akan mengalami sebuah proses kehidupan yang dimulai dari kelahiran hingga kematian (Arifin, 2016). Demikianlah, manusia pasti akan sampai pada akhir kehidupannya, kematian akan menyapa semua manusia tanpa terkecuali (Mubarak, 2015).

Menurut penafsiran Shihab (2007) pada surah AlAnkabut (29):57 menjelaskan bahwa Dan hendaklah kamu mengetahui dan menyadari bahwa cepat atau lambat kamu pasti akan mati karena setiap yang berjiwa akan merasakan mati. Kemudian, setelah kematian dan kebangkitan dari kubur, hanya kepada Kami saja kamu dikembalikan, baik yang mukmin yang sempurna iman dan amalnya maupun yang sekadar beriman tanpa amal saleh, demikian juga yang kafir.

Saat seseorang meninggal maka akan diperlukan sepetak lahan untuk mengubur jasadnya (Arifin, 2016). Penguburan merupakan sunnatullah yang sudah berlaku sejak pertama kali adanya mayat di muka bumi ini (Istiqomah, 2016). Prosesi pemakaman jenazah dalam tanah sebenarnya merupakan pemuliaan kepada jenazah itu sendiri terutama kaum Muslimin karena kita telah mengembalikannya ke tempat asal penciptaannya, yaitu tanah (Yasir, 2016).

Peran tanah yang semakin vital membawa persoalan baru bagi masyarakat dan pihak-pihak terkait yakni ketidakseimbangan antara permintaan dan penawaran tanah memunculkan fenomena penting (Affandy, 2015). Jumlah manusia dan aktivitas beserta berbagai unsur buatannya akan terus bertambah, sedangkan alam tidak berkembang bahkan terus menerus dipaksa, didesak, dan diubah untuk dapat menampung (Kuswartojo et.al, 2005). Perkembangan aktivitas penduduk menyebabkan lahan yang tersedia lebih difokuskan kepada penyediaan lahan untuk permukiman penduduk serta kegiatan perekonomian (Wulandari, 2014).

Kebutuhan tanah bagi kepentingan umum salah satunya adalah untuk tanah pemakaman (Affandy, 2015). Pengelolaan tempat pemakaman umum atau TPU merupakan salah satu fasilitas yang harus dimiliki suatu kota (Tukiman, 2007). Tempat pemakaman umum merupakan jenis pemanfaatan lahan yang bersifat LULU (Locally Unwanted Land Use) yaitu lahan yang berfungsi untuk kegiatan yang mutlak diperlukan namun tidak diinginkan keberadaanya (Aji, Suprayogi, \& Wijaya, 2015).
Beberapa macam makam baik yang dibedakan berdasarkan agama maupun hal lain, pemakaman berdasarkan agama contohnya makam Islam dan makam Nasrani sedangkan klasifikasi makam juga dapat didasarkan pada hal lain misalnya makam Pahlawan dan makam Cina. Penyebutan macam-macam makam tersebut berkaitan dengan peruntukan orang yang dimakaman dan status tanah (Affandy, 2015).

Keberagaman jenis tempat pemakaman di Indonesia menandakan bahwa pemenuhan kebutuhan tanah pemakaman bagi masyarakat Indonesia tidak masalah. Namun realita didalam masyarakat menunjukkan sebaliknya. Hal ini dapat dilihat dalam pemberitaan berbagai media massa maupun eletronika yang akhirakhir ini menunjukkan banyaknya permasalahan mengenai tanah pemakaman (Affandy, 2015). Permasalahan lahan pemakaman dalam kehidupan bermasyarakat sudah menjadi salah satu masalah sosial dalam kehidupan bangsa Indonesia khususnya di Kota Makassar (Adhyaksa, 2017).

Salah satu kasus yang pernah terjadi di Kota Makassar yakni salah satu keluarga terpaksa menunda penguburan keluarganya yang meninggal dunia dikarenakan tidak memiliki kemampuan untuk mengurus segala hal yang terkait dengan pengadaan atau pembelian perlengkapan mayat (Adhyaksa, 2017). Kelangkaan ketersediaan lahan untuk pemakaman menjadikan masyarakat yang membutuhkan tanah pemakaman semakin sulit memenuhi kebutuhannya akan tanah pemakaman (Affandy, 2015).

Kota Makassar memiliki luas wilayah sebesar 175,77 $\mathrm{km}^{2}$ dengan jumlah penduduk di tahun 2016 sebanyak 1.469.601 jiwa sehingga tingkat kepadatan penduduk mencapai 8.361 jiwa $/ \mathrm{km}^{2}$. Peningkatan jumlah penduduk Kota Makassar dari tahun 2014-2016 berbanding lurus dengan peningkatan jumlah kematian pula yakni di tahun 2013 jumlah kematian sebanyak 3.252 jiwa, kemudian di tahun 2014 sebanyak 3.177 jiwa, di tahun 2015 meningkat sebanyak 3.251 jiwa dan terus meningkat di tahun 2016 menjadi 3.434 jiwa sehingga rata-rata angka kematian di Kota Makassar dari tahun 2012-2016 mencapai 3,224 jiwa yang meninggal per tahun (Dinas Lingkungan Hidup Kota Makassar, 2017).

Menurut Farhan (2016) pertambahan penduduk yang terus meningkat, baik akibat dari faktor kelahiran maupun urbanisasi secara tidak langsung membuat angka kematian ikut meningkat juga merupakan salah satu faktor permasalahan lahan pemakaman. Dengan demikian, kebutuhan lahan untuk pemakaman tiap tahunnya pun juga akan terus bertambah sesuai dengan pertambahan jumlah penduduk yang sangat pesat (Adhyaksa, 2017).

Populasi penduduk yang semakin bertambah dan akan mengalami kematian setiap saat tentu memerlukan sebuah lahan untuk dimakamkan, terkhususnya untuk seorang muslim yang ketika meninggal akan dikubur 
sedangkan lahan pemakaman saat ini semakin terbatas. Hal ini menunjukkan adanya ketidakseimbangan antara jumlah kematian dan luas lahan pemakaman yang tersedia sehingga muncullah beberapa permasalahan tentang lahan pemakaman. Penelitian ini penting untuk dilakukan agar mampu memberikan inovasi pengembangan lahan pemakaman sesuai dengan aspek penataan ruang dalam hal ini menjaga pemanfaatan lahan perkotaan yang berkelanjutan.

\section{B. METODE PENELITIAN}

Penelitian ini dilakukan di Kota Makassar dengan fokus penelitian pada lahan pemakaman umum Islam di Kota Makassar milik pemerintah yang saat ini terdapat 5 tempat pemakaman umum diantaranya TPU Islam Dadi, TPU Islam Beroanging, TPU Islam Paropo, TPU Islam Maccini dan TPU Islam Sudiang Raya.

Teknik pengumpulan data berupa observasi untuk mengetahui kondisi eksisting lahan pemakaman umum Islam, wawancara dengan para mandor untuk memperoleh kondisi setiap TPU Islam dan wawancara dengan sopir jenazah untuk memperoleh informasi jumlah jenazah yang dimakamkan didalam maupun diluar Kota Makassar, metode instansional untuk mendapatkan data angka kematian dan jumlah penduduk yang dilakukan di Dinas Kependudukan \& Catatan Sipil, Dinas Lingkungan Hidup dan Badan Pusat Statistik, kepustakaan untuk mendapatkan literatur/referensi terkait dengan penelitian berupa buku, laporan, jurnal penelitian maupun artikel yang didapatkan melalui internet serta studi dokumentasi. Teknik analisis yang digunakan adalah analisis deskriptif untuk menggambarkan secara sistematis mengenai kondisi lahan pemakaman islam, analisis proyeksi penduduk dengan menggunakan rumus extrapolasi untuk mengetahui jumlah penduduk dan jumlah angka kematian di masa mendatang:

$\mathrm{Pt}=\mathrm{Po}+\mathrm{f}(\mathrm{t}-\mathrm{o})$

Keterangan :

$\mathrm{Pt} \quad=$ penduduk pada tahun $\mathrm{t}$

Po = penduduk pada tahun dasar

(t-o) = selisih antara tahun dasar dengan tahun yang diramalkan, yang sering disingkat dengan $n$

$\mathrm{f} \quad=$ fungsi perkembangan penduduk.

Serta analisis daya tampung untuk mengetahui ambang batas lahan pemakaman di Kota Makassar dengan menghitung luasan lahan pemakaman yang akan dibagi dengan luasan setiap makam.

\section{HASIL DAN PEMBAHASAN}

\section{Gambaran Umum Wilayah Kota Makassar}

Sebagai Ibu Kota Provinsi Sulawesi Selatan, Kota

Makassar terletak di ujung selatan Pulau Sulawesi dengan cakupan wilayah merupakan wilayah pesisir dan bahkan mempunyai 5 pulau dimana terdapat di kelurahan yang berada di pulau. Secara astronomis, Kota Makassar terletak antara $119^{\circ} 24^{\prime} 17^{\prime} 28^{\prime \prime}$ Bujur Timur dan
5 8'6'19" Lintang Selatan. Selain itu, Kota Makassar juga terdiri dari 15 kecamatan dan terbagi dalam 153 kelurahan, 996 RW dan 4.964 RT.

\section{Perbandingan Persentase Pertumbuhan Jumlah Penduduk dengan Kematian}

Pertumbuhan jumlah penduduk di Kota Makassar menunjukkan persentase pertumbuhannya meningkat dari tahun 2013-2017 dengan pertumbuhan penduduknya rata-rata hanya $0,32 \%$ yakni sebanyak 5.336 jiwa sedangkan persentase pertumbuhan jumlah kematian di Kota Makassar juga meningkat dengan ratarata pertumbuhan 2,54\% yakni sebanyak 82 jiwa. Hal ini menunjukkan bahwa setiap tahunnya dari jumlah penduduk sebanyak 5.336 jiwa terdapat kematian 82 jiwa/tahun.

Tabel 1

Persentase Pertumbuhan Jumlah Penduduk dengan Jumlah Kematian di Kota Makassar

\begin{tabular}{cccccccc}
$\begin{array}{l}\mathbf{N} \\
\text { o }\end{array}$ & Tahun & $\begin{array}{c}\text { Jumlah } \\
\text { Penduduk } \\
\text { (jiwa) }\end{array}$ & $\begin{array}{c}\text { Pertamb } \\
\text { ahan } \\
\text { (jiwa) }\end{array}$ & \% & $\begin{array}{c}\text { Jumlah } \\
\text { Kematia } \\
\text { n (jiwa) }\end{array}$ & $\begin{array}{c}\text { Pertam } \\
\text { bahan } \\
\text { (jiwa) }\end{array}$ & \% \\
\hline 1 & 2014 & $1,652,305$ & - & - & 3,177 & - & - \\
2 & 2015 & $1,653,386$ & 1,081 & 0.07 & 3,251 & 74 & 2.33 \\
3 & 2016 & $1,658,503$ & 5,117 & 0.31 & 3,434 & 183 & 5.63 \\
4 & 2017 & $1,668,314$ & 9,811 & 0.59 & 3,422 & -12 & -0.35 \\
\multicolumn{2}{r}{ Jumlah } & $8,040,580$ & 16,009 & 0.97 & 16,536 & 245 & 7.61 \\
\hline \multicolumn{2}{r}{ Rata-rata } & $1,608,116$ & 5,336 & 0.32 & 3,307 & 82 & 2.54 \\
\hline
\end{tabular}

Sumber: Dinas Kependudukan \& Catatan Sipil dan Dinas Lingkungan Hidup, 2018

\section{Identifikasi Tempat Pemakaman Umum Islam \\ a. TPU Islam Dadi}

Pemakaman Islam Dadi terdapat di Kelurahan Maricayya Selatan, Kecamatan Mamajang yang dibuka sejak zaman belanda kemudian ditutup di tahun 1998 dengan luas lahan $33.148 \mathrm{~m}^{2}$. Pada tanggal 12 Desember 2005, pemerintah menyatakan bahwa TPU Islam Dadi dibuka kembali dengan sistem penumpukan makam bagi mereka yang mempunyai keluarga dalam TPU tersebut dan masih berlangsung hingga saat ini.

\section{b. TPU Islam Beroanging}

Pemakaman Islam Beroanging memiliki luas lahan 45.974 m2 yang terdapat di Kelurahan Pannampu, Kecamatan Tallo yang dibuka sejak zaman Belanda. Kemudian ditahun 1996 ditutup karena telah penuh dan dibuka kembali ditahun 2005 dengan sistem penumpukan makam bagi mereka yang memiliki keluarga yang terdapat dalam TPU tersebut.

\section{c. TPU Islam Paropo}

Pemakaman Islam Paropo memiliki luas lahan 58.500 m2 yang terdapat di Kelurahan Paropo, Kecamatan Panakkukang dan dibuka sejak tahun 1958 hingga tahun 1985 telah penuh. Akan tetapi di bulan oktober 1998 ditutup kembali dan dibuka lagi ini di tahun 2005 hingga sekarang dengan sistem tumpuk bagi yang memiliki hubungan keluarga dalam TPU tersebut.

\section{d. TPU Islam Maccini}

Pemakaman Islam Maccini terdapat di Kelurahan Maccini, Kecamatan Makassar dengan luas lahan sebesar $18.758 \mathrm{~m}^{2}$ yang dibuka sejak zaman belanda 
kemudian ditutup ditahun 1976 karena telah penuh. Hingga saat ini, TPU Islam Maccini belum dibuka karena masih dalam keadaan pemeliharaan.

e. TPU Islam Sudiang Raya

Pemakaman Islam Dadi memiliki 125.00o m2 yang terdapat di Kelurahan Sudiang Raya, Kecamatan Biringkanaya dan dibuka pada tanggal 6 bulan juni tahun 1996 dan masih aktif saat ini. Pemakaman ini merupakan makam baru namun terdapat juga beberapa makam yang telah ditumpuk.

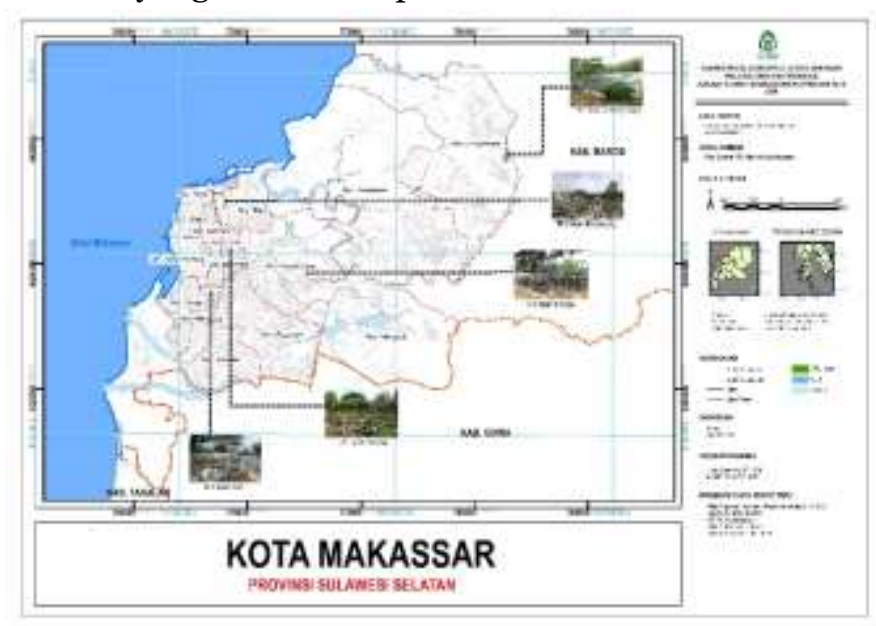

Gambar 1. Peta Sebaran TPU Islam di Kota Makassar

\section{Kondisi Tempat Pemakaman Umum Islam}

a. Luasan Lahan Makam

Kota Makassar memiliki 5 TPU Islam milik pemerintah dengan total luas lahan sebanyak 281.382 m2 atau 28,13 ha. Dari ke-5 lokasi TPU Islam tersebut terdapat 3 lokasi yang telah penuh yaitu TPU Islam Dadi, Beroanging dan Paropo tapi masih digunakan dengan sistem tumpuk sedangkan untuk TPU Islam Maccini juga telah penuh namun saat ini tidak digunakan karena berada dalam tahap pemeliharaan.Lokasi pemakaman yang masih memiliki lahan kosong yaitu TPU Islam Sudiang Raya dengan sisa lahan sebanyak 0,93 ha.

\section{b. Sistem Penumpukan}

Penumpukan dilakukan untuk mereka yang memiliki hubungan keluarga dengan selang waktu minimal 5 tahun. Berdasarkan hasil wawancara dengan para mandor dan pengawas di setiap TPU menyatakan bahwa sistem tumpuk terdapat dua cara yaitu sistem tumpuk susun dan sistem tumpuk berdampingan.

\section{c. Pola Penataan Makam}

Ketidakteraturan makam terdapat di 4 lokasi TPU Islam seperti Dadi, Beroanging, Paropo dan Maccini yang disebabkan karena tidak adanya jarak antar makam, ukuran makam dan bentuk makam yang berbeda-beda. Sedangkan untuk TPU Islam Sudiang Raya masih terlihat teratur namun terdapat pula makam yang tidak memiliki jarak dengan makam lainnya disebabkan adanya renovasi makam seperti menembok sehingga luasan makam akan bertambah dengan mengambil lahan yang sebelumnya disediakan sebagai jarak antar makam.

\section{d. Aktivitas di Makam}

Aktivitas lain yang dilakukan oleh masyarakat sekitar TPU seperti menjemur pakaian di bagian pagar makam, tidur di atas makam yang telah direnovasi, makan dan minum disekitaran makam, menidurkan bayi mereka diatas makam dengan membuat ayunan di atas makam yang memiliki pagar, berjualan didalam makam, tempat bermain anak-anak (main bola) dan tempat berkumpul masyarakat sekitar TPU.

\section{Daya Tampung sebagai Ambang Batas}

Penelitian ini dilakukan di Kota Makassar dengan fokus penelitian pada lahan pemakaman umum Islam di Kota Makassar milik pemerintah yang saat ini terdapat 5 tempat pemakaman umum diantaranya TPU Islam Dadi, TPU Islam Beroanging, TPU Islam Paropo, TPU Islam Maccini dan TPU Islam Sudiang Raya.

Tabel 2

Proyeksi Kematian Agama Islam untuk 20 tahun kedepan dirinci per 5 tahun

\begin{tabular}{ccr}
\hline No & Tahun & $\begin{array}{c}\text { Jumlah Penduduk } \\
\text { (jiwa) }\end{array}$ \\
\hline 1 & 2022 & 3,830 \\
2 & 2027 & 4,239 \\
3 & 2032 & 4,647 \\
4 & 2037 & 5,055 \\
\hline Sumber: Hasil Analisis, 2018
\end{tabular}

\section{Sumber: Hasil Analisis, 2018}

Estimasi jumlah lahan yang digunakan masyarakat Kota Makassar diperhitungkan menggunakan standar ukuran makam sebesar 2,5 m x 1,5 m yang sudah termasuk jarak antar makam sedangkan estimasi kebutuhan lahan pemakaman berdasarkan kondisi dilapangan sebesar $2 \mathrm{~m}$ x $1 \mathrm{~m}$.

\section{Tabel 3}

Estimasi Kebutuhan Lahan Pemakaman di Kota Makassar dalam 20 tahun kedepan

\begin{tabular}{c|c|r|r|r}
\hline No & Tahun & $\begin{array}{c}\text { Jumlah } \\
\text { Kematian } \\
\text { (jiwa) }\end{array}$ & $\begin{array}{c}\text { Jumlah Lahan } \\
\text { yang akan } \\
\text { digunakan } \\
\text { untuk ukuran } \\
2.5 \mathrm{~m} \mathrm{x} \mathrm{1.5} \mathrm{m} \\
\text { (ha) }\end{array}$ & $\begin{array}{c}\text { Jumlah Lahan } \\
\text { yang akan } \\
\text { digunakan } \\
\text { untuk ukuran } \\
2 \mathrm{~m} \mathrm{x} \mathrm{1} \mathrm{m} \mathrm{(ha)}\end{array}$ \\
\hline 1 & 2022 & 3,380 & 1.27 & 0.68 \\
\hline 2 & 2027 & 4,239 & 1.59 & 0.85 \\
\hline 3 & 2032 & 4,647 & 1.74 & 0.93 \\
\hline 4 & 2037 & 5,055 & 1.90 & 1.01 \\
\hline \multicolumn{7}{c}{ Total } & 17,771 & 6.50 & 3.46 \\
\hline
\end{tabular}

Sumber: Hasil Analisis, 2018

Lahan yang tersisa dari 5 lokasi TPU Islam adalah $\pm 0,93$ ha yang hanya terdapat di TPU Sudiang Raya karena ke-4 lokasi TPU Islam lainnya telah penuh. Dengan sisa lahan tersebut maka daya tampungnya hanya mampu memenuhi kebutuhan makam sebanyak 2.480 makam dengan ukuran $2,5 \mathrm{~m}$ x 1,5 m sedangkan untuk ukuran $2 \mathrm{~m}$ x $1 \mathrm{~m}$ sebanyak 4.650 makam. 
Tabel 4

Ambang Batas Kebutuhan Lahan Pemakaman di Kota Makassar

\begin{tabular}{rrrrr}
\hline No & Tahun $\begin{array}{c}\text { Jumlah } \\
\text { Kematian } \\
\text { (jiwa) }\end{array}$ & $\begin{array}{c}\text { Kebutuhan } \\
\text { Lahan Makam } \\
\text { Ukuran 2.5 m x } \\
1.5 \mathrm{~m} \text { (ha) }\end{array}$ & $\begin{array}{c}\text { Kebutuhan } \\
\text { Lahan Makam } \\
\text { Ukuran 2 m x 1 } \\
\text { m (ha) }\end{array}$ \\
\hline 1 & 2022 & 3,380 & 0.93 & 0.93 \\
2 & 2027 & 4,239 & 0 & 0.25 \\
3 & 2032 & 4,647 & 0 & 0 \\
4 & 2037 & 5,055 & 0 & 0 \\
\hline
\end{tabular}

Sumber: Hasil Analisis, 2018

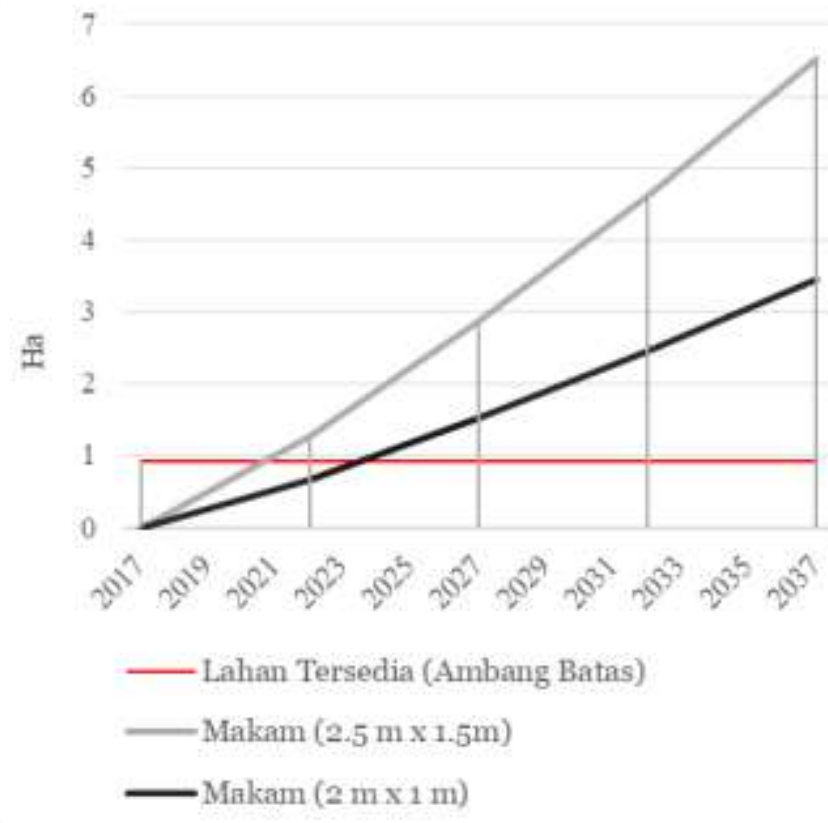

Gambar 2. Grafik Ambang Batas Pemakaman

Penerapan sistem penumpukan dapat menampung jumlah kematian hingga beberapa tahun kedepan sehingga dapat dilakukan analisis mengenai ambang batas kebutuhan lahan pemakaman dengan standar penumpukan 2 orang dalam satu makam.

Tabel 5

Daya Tampung Lahan TPU Islam di Kota Makassar dengan Sistem Tumpuk

\begin{tabular}{crr}
\hline Sistem & \multicolumn{1}{c}{ Daya Tampung } & Daya Tampung \\
Pemakaman & untuk Ukuran 2.5 m & $\begin{array}{c}\text { untuk Ukuran 2 m } \\
\text { x 1.5 m (jiwa/petak) }\end{array}$ \\
& 2,480 & 4,650 \\
Normal & jiwa/petak) \\
Menumpuk & 4,960 & 9,300 \\
\hline
\end{tabular}

Sumber: Hasil Analisis, 2018

Tabel 6

Ambang Batas Daya Tampung Lahan Pemakaman dengan Sistem Tumpuk

\begin{tabular}{rrrrr}
\hline No & Tahun & $\begin{array}{c}\text { Jumlah } \\
\text { Kematian } \\
\text { (jiwa) }\end{array}$ & $\begin{array}{c}\text { Daya Tampung } \\
\text { untuk Ukuran } \\
2.5 \mathrm{~m} \times 1.5 \mathrm{~m} \\
\text { (jiwa/petak) }\end{array}$ & $\begin{array}{c}\text { Daya Tampung } \\
\text { untuk Ukuran 2 } \\
\mathrm{m} \times 1 \mathrm{~m} \\
\text { (jiwa/petak) }\end{array}$ \\
\hline 1 & 2022 & 3,380 & 4,960 & 9,300 \\
2 & 2027 & 4,239 & 1,130 & 5,470 \\
3 & 2032 & 4,647 & 0 & 1,231 \\
4 & 2037 & 5,055 & 0 & 0 \\
\hline
\end{tabular}

Sumber: Hasil Analisis, 2018

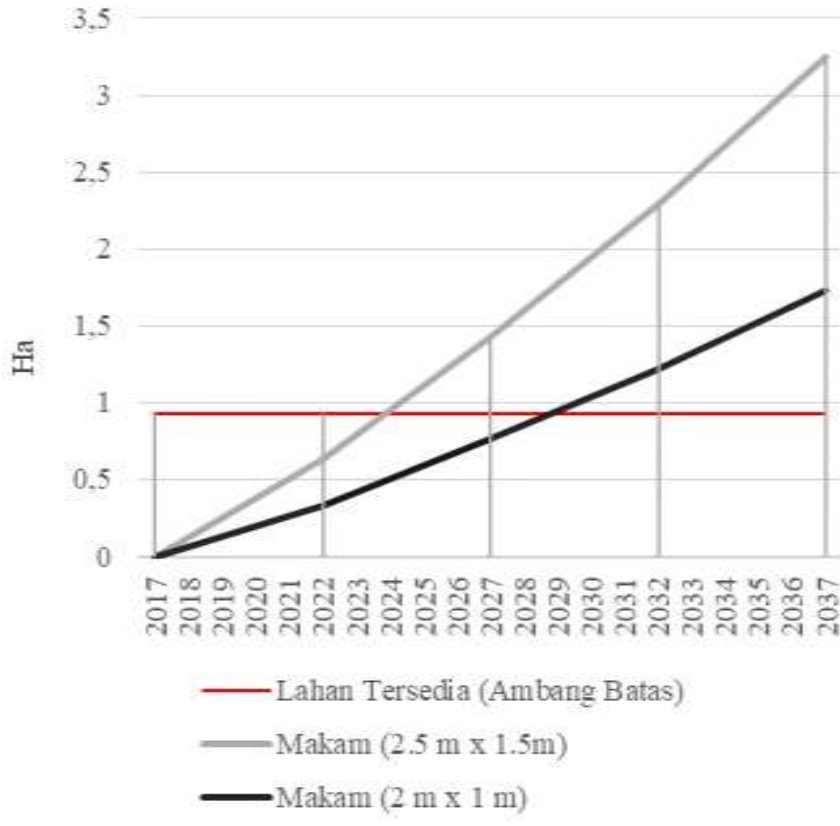

Gambar 3. Grafik Ambang Batas Kebutuhan Lahan Pemakaman dengan Sistem Tumpuk

\section{Arahan Perencanaan dalam Pengembangan Pemenuhan Kebutuhan Lahan Pemakaman ditinjau dari Aspek Tata Ruang}

a. Peruntukan Makam untuk Masyarakat Kota Makassar

Lahan pemakaman yang tersisa hingga saat ini sebaiknya hanya diperuntukkan untuk masyarakat Kota Makassar saja dengan syarat memperlihatkan kartu tanda pengenal kepada pihak pelayanan pemakaman kemudian dilaporkan kepada Dinas Kependudukan dan Catatan Sipil Kota Makassar sehingga terjadi sinkronisasi mengenai data jumlah penduduk.

b. Pengoptimalisasian Lahan Pemakaman

Pengoptimalisasian dilakukan dengan penerapan sistem per blok, dalam satu blok memiliki ukuran $5 \mathrm{~m} \times 3$ $\mathrm{m}$ yang terdapat 2 makam dengan ukuran satu makam 2 $\mathrm{m} \times 1 \mathrm{~m}$ yang setiap sisinya terdapat jarak antar makam sebanyak $1 \mathrm{~m}$. Ukuran $1 \mathrm{~m}$ ini akan dijadikan sebagai pekarangan makam sebanyak $0.35 \mathrm{~m}$ dibagian sisi kiri atau kanan (samping jalan) dan 0.10 m disetiap sisi atas dan bawahnya sedangkan untuk jalan setapak makam memiliki ukuran $0.30 \mathrm{~m}$ yang diperuntukkan untuk peziarah agar tidak melangkahi makam ataupun menginjaknya.

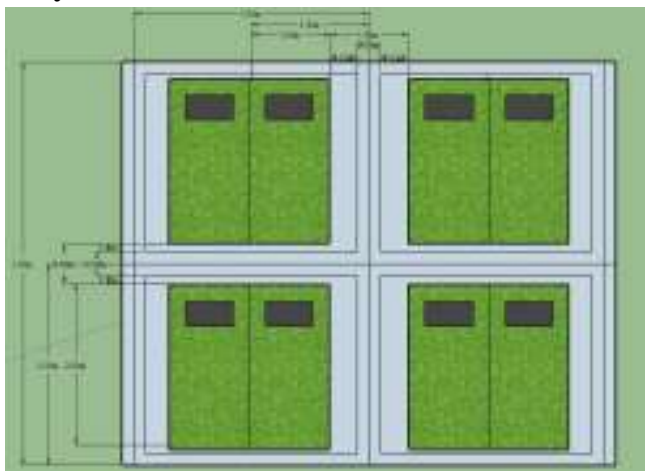


Gambar 4. Ukuran Makam dan Model Sistem Blok

\section{c. Sistem Penumpukan Makam}

Sistem penumpukan yang dimaksud seperti halnya dengan pemakaman baqi' di Madinah yaitu menumpuk makam jika semua makam telah terpakai sehingga meski terdapat puluhan mayat yang meninggal dalam sehari namun setiap mayat akan mengisi satu makam.

\section{d. Hutan Lindung sebagai Tempat Pemakaman} Umum

Keadaan ini tentu tidak akan mengubah dan menganggu fungsi utama kawasan hutan lindung karena didalam kawasan tersebut tidak akan ada aktivitas dunia yang terjadi hanya saja aktivitas seperti menggali kubur dan melakukan ziarah. Keadaan ini tentu memberikan kenyamanan terhadap peziarah karena adanya pohonpohon tersebut memberikan udara yang segar dan suasana yang sejuk tanpa harus berpanas-panasan seperti kondisi saat ini.

\section{e. Pemakaman Berdiri}

Pemakaman berdiri adalah salah satu metode yang dilakukan dengan memasukkan jenazah kedalam tanah dengan posisi diberdirikan sehingga ukuran setiap makam hanya membutuhkan $\pm 50 \mathrm{~cm} \times 50 \mathrm{~cm}$ dengan tingkat kedalaman disesuaikan dengan tinggi jenazah.

\section{f. Pemindahan Makam}

Memindahkan makam setelah mencapai waktu tertentu yang akan dilakukan dengan proses penggalian dan kremasi kemudian hasil dari kremasi disimpan didalam gedung atau hasil dari kremasi tersebut dikubur kembali disuatu pemakaman lain khusus sebagai kawasan penguburan abu kremasi.

\section{g. Pembuangan Abu Kremasi}

Tradisi pemakaman dengan melakukan pelarungan abu anggota keluarga ke laut namun umumnya dilakukan oleh penganut agama hindu.

\section{h. Pemakaman Terpadu}

Kerja sama antar daerah untuk pengadaan pemakaman terpadu dengan melibatkan beberapa Kabupaten yang termasuk dalam wilayah Mamminasata namun pihak Kota Makassar tetap memberikan sumbangsih dalam pengadaan lahan pemakaman tersebut seperti biaya pembebasan lahan yang ditanggung dan lain sebagainya.Tradisi pemakaman dengan melakukan pelarungan abu anggota keluarga ke laut namun umumnya dilakukan oleh penganut agama hindu.

\section{i. Pemakaman Ideal}

Ketika seorang muslim meninggal dunia maka prosesi yang dilakukan harus sesuai dengan syariat Islam seperti halnya dalam tahap penguburan jenazah. Pengadaan pemakaman ideal ini merupakan model pemakaman yang sesuai dengan syariat islam.

1) Terdapat tanda batu atau lainnya diatas setiap makam

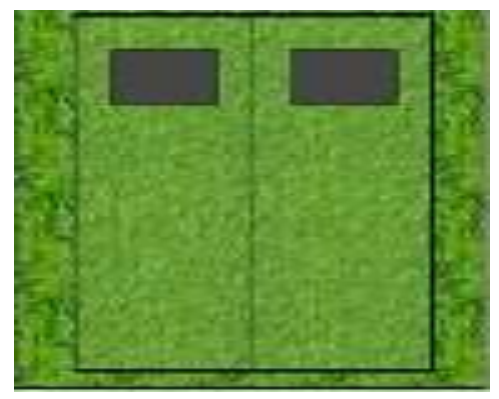

Gambar 5. Ilustrasi Bentuk Setiap Makam

2) Tidak diperbolehkan menulis dan menambahkan sesuatu diatas kuburan sehingga setiap makam terlihat sederhana yang hanya terdiri dari gundukan tanah

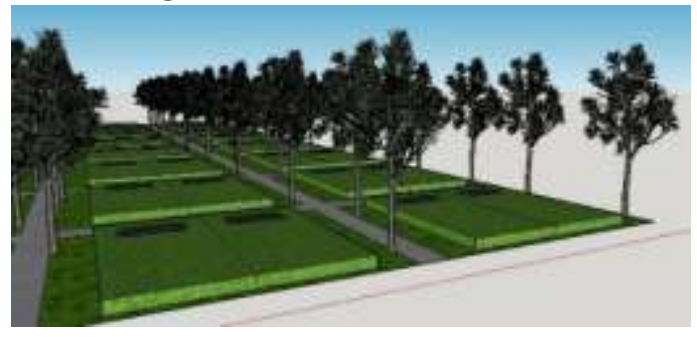

Gambar 6. Ilustrasi Model Pemakaman yang sesuai Syariat Islam

3) Makam tidak diperbolehkan untuk dilangkahi, diduduki dan diinjak-injak sehingga antara makam terdapat jalan setapak

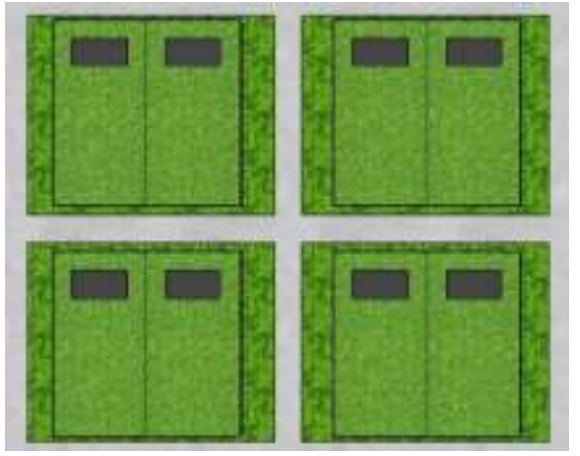

Gambar 7. Ilustrasi Jalan Setapak diantara Makam

4) Membuat papan informasi sebagai bentuk sosialisasi ke masyarakat mengenai model pemakaman yang sesuai syariat islam

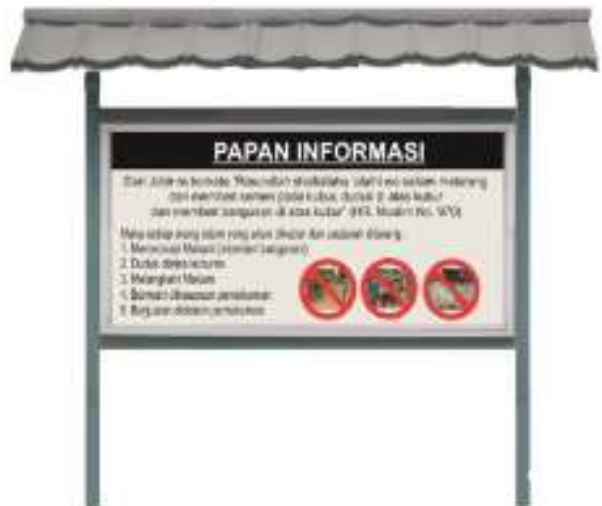

Gambar 8. Ilustrasi Papan Informasi disetiap Pemakaman 


\section{SIMPULAN DAN SARAN}

\section{Simpulan}

Besaran ambang batas lahan pemakaman umum islam di Kota Makassar dengan menggunakan analisis daya tampung menunjukkan bahwa daya tampung lahan pemakaman Islam Kota Makassar masih mampu menampung hingga tahun 2023 dengan sistem normal sedangkan untuk sistem tumpuk mampu menampung hingga tahun 2029. Adapun Arahan perencanaan dalam pengembangan pemenuhan kebutuhan lahan pemakaman ditinjau dari aspek tata ruang dapat dilakukan dengan berbagai cara yaitu : peruntukan makam untuk masyarakat Kota Makassar, pengoptimalisasian lahan pemakaman, sistem penumpukan makam, hutan lindung sebagai tempat pemakaman umum, pemakaman berdiri, pemindahan makam, pembuangan abu kremasi, pemakaman terpadu dan pemakaman ideal. Namun berdasarkan tinjauan hukum islam tentang penguburan jenazah maka solusi yang dapat dilakukan adalah peruntukan makam untuk masyarakat Kota Makassar, pengoptimalisasian lahan pemakaman, menjadikan hutan lindung sebagai tempat pemakaman umum, membuat sistem pemakaman terpadu dan pemakaman ideal serta sistem penumpukan jika kondisi lahan sudah tidak ada lagi yang tersedia.

\section{Saran}

a. Bagi Pemerintah

1) Membuat aturan yang tegas akan ketertiban didalam pemakaman, aturan yang terkait dengan sistem penumpukan, dan aturan mengenai memberi bangunan diatas kuburan

2) Melakukan kerja sama dengan Kabupaten tetangga yang tergabung dalam Mamminasata.

3) Segera menetapkan solusi sebelum lahan yang tersisa saat ini menjadi penuh lagi, sehingga dapat memenuhi kebutuhan lahan pemakaman di Kota Makassar.

4) Menghimbau kepada masyarakat Kota Makassar agar tradisi pemakaman yang saat ini terjadi dilapangan ditinggalkan dan mulai menggunakan model pemakaman yang sesuai dengan syariat islam.

5) Kawasan reklamasi dapat pula dibebaskan lahan untuk diperuntukkan kawasan pemakaman terpadu yang sesuai dengan syariat islam dan menjadi pemakaman percontohan.

b. Bagi Penulis yang ingin melanjutkan penelitian ini dapat menganalisis lahan pemakaman umum untuk semua agama agar hasil yang didapat dalam penelitian tentang lahan pemakaman di Kota Makassar ini lebih lengkap.

\section{DAFTAR RUJUKAN}

[1] Adhyaksa, A. (2017). Tinjauan Hukum Administrasi Negara Terhadap Pelayanan Pemakaman Di Kota Makassar. Makassar: Universitas Hasanuddin.

[2] Affandy, S. (2015). Tinjauan Hukum Islam terhadap Praktik Jual Beli Tanah Pemakaman Modern di Kabupaten Karawang. Yogyakarta: Universitas Islam Negeri Sunan Kalijaga.

[3] Agustiar, A. A. (2017). Laporan Praktikum Teknik Pengujian Mutu Hasil Perikanan Uji Treshold. Yogyakarta: Universitas Gadjah Mada.

[4] Aji, A. S., Suprayogi, A., \& Wijaya, A. P. (2015). Analisis Kesesuaian Kawasan Peruntukan Pemakaman Umum Baru Berbasis Sistem Informasi Geografis. Jurnal Geodesi Undip Vol.4 No.3, 100.

[5] Amalia, G. (2016). Ketersediaan Lahan Tempat Pemakaman Umum (TPU) di Kota Makassar. Yogyakarta: Universitas Gadjah Mada.

[6] Amin, A. S. (2011). Kajian Ayat-Ayat Al-Qur'an yang Berhubungan dengan Perkembangan Embrio Pada Manusia. Semarang: Institut Agama Islam Negeri Walisongo.

[7] Arifin, Y. N. (2016). Optimalisasi Usaha Penyediaan Lahan Pemakaman dalam Kawasan Perumahan di Kabupaten Boyolali. Jurnal Geografi Volume 13 No.1, 80.

[8] Badan Pusat Statistik Kota Makassar Tahun 2017.

[9] Basit, A. (2014). Kematian dalam Al-Qur'an : Perspektif Ibn Kathir. Jakarta: Universitas Islam Negeri Syarif Hidayatullah.

[10]Departemen Agama RI. (2007). Al-Qur'an dan Terjemahannya. Jakarta: CV Darus Sunnah.

[11] Farhan, N. (2016). Estimasi Kebutuhan Lahan Pemakaman Di Kota Banda Aceh. Jurnal Ilmiah Mahasiswa (JIM) Vol.1 No.1, 152-153.

[12] Firman, T. (2018, Februari 19). Tren Kremasi Jenazah Meningkat Akibat Lahan Kuburan Makin Sempit. Retrieved from tirto.id: https://tirto.id/tren-kremasijenazah-meningkat-akibat-lahan-kuburan-makinsempit-cEYr.

[13] Istiqomah, Y. L. (2016, Juli 30). Kehormatan Muslim Yang Telah Meninggal Tetap Terjaga. Retrieved from almanhaj.or.id: $\quad$ https://almanhaj.or.id/5452kehormatan-muslim-yang-telah-meninggal-tetapterjaga.html.

[14] Jawas, Y. '. (2010, November 5). Proses Penciptaan Manusia dan Ditetapkannya Amalan Hamba (1). Retrieved from almanhaj.or.id: https://almanhaj.or.id/2884-proses-penciptaanmanusia-dan-ditetapkannya-amalan-hamba-1.html.

[15] Jalaluddin, M. (2013). Analisis Kesesuaian dan Ketersediaan Lahan serta Arahan Pengembangan Komoditas Pertanian di Kabupaten Kepulauan Meranti Provinsi Riau. Bogor: Institut Pertanian Bogor.

[16] Kartikasari, D. (2011). Pengaruh Luas Lahan, Modal, dan Tenaga Kerja terhadap Hasil Produksi Padi di Kecamatan Keling Kabupaten Jepara. Semarang: Universitas Negeri Semarang.

[17] Keputusan Menteri Dalam Negeri Nomor 26 Tahun 1989 tentang Pedoman Pelaksanaan Peraturan Pemerintah Nomor 9 Tahun 1987 tentang Penyediaan dan Penggunaan Tanah untuk Keperluan Tempat Pemakaman.

[18] Kozlowski, J. (1997). Pendekatan Ambang Batas Dalam Perencanaan Kota, Wilayah dan Lingkungan Teori dan 
Praktek. Jakarta: Penerbit Universitas Indonesia (UIPress).

[19] Kurniawati, F. E. (2010). Perkembangan Struktur Ruang Kota Semarang Periode 1960-2007 (Studi Pengembangan Struktur Ruang dari Masa Pasca Kolonial Sampai 2007). Surakarta: Universitas Muhammadiyah Surakarta.

[20] Kuswartojo, T., Rosnarti, D., Effendi, V., K, R. E., \& Sadi, P. (2005). Perumahan dan Permukiman Indonesia. Bandung: Penerbit ITB.

[21] Muaz. (2014, Desember 27). Hukum Menimpa (Replace) Jenazah. Retrieved from muidkijakarta.or.id: http://www.muidkijakarta.or.id/hukum-menimpareplace-jenazah/.

[22]Muta'ali, L. (2012). Daya Dukung Lingkungan untuk Perencanaan Pengembangan Wilayah. Yogyakarta: Badan Penerbit Fakultas Geografi (BPFG).

[23]Muta'ali, L. (2015). Teknik Analisis Regional. Yogyakarta: Badan Penerbit Fakultas Geografi (BPFG).

[24]Notohadiprawiro, T. (2006). Kemampuan dan Kesesuaian Lahan : Pengertian dan Penetapannya. Yogyakarta: Ilmu Tanah Universitas Gadjah Mada.

[25]Peraturan Menteri Pekerjaan Umum Nomor 5 Tahun 2008 tentang Pedoman Penyediaan Dan Pemanfaatan Ruang Terbuka Hijau Di Kawasan Perkotaan.

[26]Peraturan Pemerintah Republik Indonesia Nomor 9 Tahun 1987 tentang Penyediaan Penggunaan Tanah untuk Keperluan Tempat Pemakaman.

[27] Peraturan Daerah Kota Makassar Nomor 8 Tahun 2009 tentang Pelayanan Pemakaman Dan Pengabuan Mayat di Kota Makassar.

[28]Sada, H. J. (2016). Manusia dalam Perspektif Agama Islam. Jurnal Pendidikan Islam Volume 7 , 130-141.

[29]Shihab, M. Q. (2005). Tafsir Al-Mishbah Pesan, Kesan dan Keserasian Al-Qur'an Volume 9. Ciputat, Jakarta: Penerbit Lentera Hati.

[30]Shihab, M. Q. (2007). Tafsir Al-Mishbah Pesan, Kesan dan Keserasian Al-Qur'an Volume 10. Pisangan, Ciputat, Tangerang: Penerbit Lentera Hati.

[31] Staf. (2018, Maret 14). Arti Makna Pengertian dan Definisi dari Nilai Ambang Batas. Retrieved from Apaarti.com: https://www.apaarti.com/nilai-ambangbatas. html.

[32]Sudaryono. (2017). Metodologi Penelitian. Tangerang: PT RajaGrafindo Persada.

[33]Sujarto , D. (2003, Januari 1). Perencanaan Tata Ruang Wilayah. Retrieved from Urban Planning \& Design Research Grup: http://www.sappk.itb.ac.id/ ppk/index.php?option=com_content\&task=view\&id $=6$ 3\&Itemid $=80$.

[34]Sugiyantoro, A. A. (2011, Mei 17). Bimbingan Mengurus Jenazah (2). Retrieved from almanhaj.or.id: https://almanhaj.or.id/3071-bimbingan-mengurusjenazah-2.html.

[35]Sofian, E. (2015). Rancang Bangun Sistem Informasi dalam Layanan dan Pemetaan Lokasi Pemakaman pada Pemakaman Umum di Wilayah Jakarta. STIMIK ESQ Volume 1 Nomvor 1, 52-54.

[36]Syahar, F. (2012). Pengaruh Faktor Artifisial terhadap Perkembangan Kota. Jurnal Skala Volume 2 Nomor 4, 50-55.

[37] Tarigan, R. (2012). Perencanaan Pembangunan Wilayah. Jakarta: Bumi Aksara.

[38]Tuasikal, M. A. (2013, Desember 9). Ringkasan Pengurusan Jenazah. Retrieved from Rumaysho.com : https://rumaysho.com/4905-ringkasanpengurusanjenazah. html.

[39]Tukiman. (2007). Implementasi Perda Nomor 13 Tahun 2003 tentang Pengelolaan Tempat Pemakaman dan Penyelenggaraan Pemakaman Jenazah. Jurnal IlmuIlmu Sosial Vol.7 No.2, 103.

[40] Undang - Undang Dasar Negara Republik Indonesia Tahun 1945.

[41] VOA. (2012, November 12). Singapura Kekurangan Lahan Pemakaman. Retrieved from VOA Indonesia: https://www.voaindonesia.com/a/singapurakekurangan-lahan-pemakaman/1554328.html.

[42]Wulandari, A. (2014). Kajian Potensi Pemakaman sebagai Ruang Terbuka Hijau Perkotaan. Langkau Betang Vol.1 No.2, 54-55.

[43]Yusuf, R. (2016). Studi Alih Fungsi Lahan Pertanian pada Kawasan Perkotaan Sungguminasa. Makassar: Universitas Islam Negeri Alauddin Makassar.

[44] Zuliyanto, A. (2015). Penataan Lokasi Pemakaman Kota Malang Berbasis Geographic Information System Menggunakan Metode Analytical Hierarchy Process (AHP). Malang: Universitas Islam Negeri Maulana Malik Ibrahim. 